\title{
Fatal Hyponatremia Associated with Preoperative Desmopressin for Bleeding Disorder
}

\author{
Joseph S Milkovic ${ }^{1+}$, Theodore E Warkentin ${ }^{2+*}$, Robert MA Richardson ${ }^{3+}$ and Ally PH Prebtani ${ }^{2+}$ \\ Correspondence: twarken@mcmaster.ca \\ ${ }^{1}$ GP Anesthetist, Halton Healthcare Services, Georgetown Hospital, Georgetown, Ontario, Canada. \\ ${ }^{2}$ Department of Pathology and Molecular Medicine, and Department of Medicine, McMaster University, Hamilton, Ontario, Canada. \\ ${ }^{3}$ Department of Medicine, University of Toronto, Toronto, Ontario, Canada.
}

\begin{abstract}
We report a 21-year-old male who underwent surgical repair of facial fractures 5 days following trauma. The patient developed rapidly progressive hyponatremia (serum sodium nadir, $123 \mathrm{mmol} / \mathrm{l}$ ) and acute cerebral edema that progressed to transtentorial herniation and death following prophylactic desmopressin $(20 \mu \mathrm{g})$ given 30 minutes preoperatively for congenital platelet function defect. Other contributing factors included a preceding 3-day prodrome of hypernatremia secondary to neurogenic diabetes insipidus (which may have made the brain more susceptible to injurious effects of perioperative acute hyponatremia) and intra-/postoperative administration of large volumes of crystalloid. This fatal adverse effect of desmopressin underscores the need for careful patient selection when using this prohemostatic agent with a major antidiuretic (water-retaining) profile.
\end{abstract}

Key words: Desmopressin, Brain injury, Trauma

\section{Background}

Desmopressin acetate, also known as 1-deamino-8-D-arginine vasopressin (DDAVP), is a vasopressin analogue that is commonly given to prevent or treat hypernatremia in the setting of central diabetes insipidus [1]. Compared with native antidiuretic hormone $(A D H)$, desmopressin exhibits tenfold greater antidiuretic power, with only $0.05 \%$ of the vasopressor activity [2]. Another effect is stimulation of the endothelium to release von Willebrand factor, making desmopressin a common agent used to prevent or treat bleeding in patients with hemostatic abnormalities such as mild or moderate von Willebrand disease [3] or various platelet function disorders $[4,5]$ or as a general prohemostatic agent to reduce transfusion needs after surgery [6]. A potential adverse effect is hyponatremia, which can be sufficiently severe to result in seizures $[7,8]$ or coma [9]. We report a patient who developed rapid-onset of hyponatremia, manifest as cerebral edema that progressed to transtentorial herniation and brain death, associated with the use of preoperative desmopressin given to reduce risk of bleeding in a young man with congenital platelet abnormality. This represents an example of a fatal complication related to the use of a common blood conservation technique.

\section{Case}

A 21-year-old male was involved in a motor vehicle accident resulting in decreased level of consciousness (Glasgow coma scale, 6) requiring intubation, hypotension responding to fluid administration, and a hemoglobin fall to $80 \mathrm{~g} / \mathrm{l}$. He sustained Lefort I and II fractures and a basal skull fracture with an associated small right subdural hematoma, right frontal and left posterior parietal contusions, but no associated mass effect or midline shift. Neurogenic (post-head injury) diabetes insipidus was diagnosed on the basis of hypernatremia (serum sodium, $151 \mathrm{mmol} /$; serum osmolality, $306 \mathrm{mmol} / \mathrm{kg}$ [normal range, 280-300 $\mathrm{mmol} / \mathrm{kg}]$ ) and inappropriate urine hypoosmolality (urine osmolality, $109 \mathrm{mmol} / \mathrm{kg}$ ), and was treated with $2 \mu \mathrm{g}$ infusions of desmopressin given four times during the first four hospital days (Figure 1A-C).

He also received cryoprecipitate and platelet transfusion on admission, followed by daily platelet transfusions, both because of his intracerebral hemorrhages, and because of a documented bleeding disorder that was first investigated after he developed severe post-tonsillectomy bleeding at age 3 . Previous investigations had revealed a non-specified platelet function defect characterized by abnormal platelet aggregation to multiple agonists (including absent aggregation to the thromboxane analogue, U46619; delayed response to collagen and borderline response to arachidonic acid). On a previous occasion, his prolonged bleeding time (20 minutes; normal 2.5-8.5 $\mathrm{min}$ ) shortened to 11.5 minutes following intravenous

(c) 2012 Warkentin et al; licensee Herbert Publications Ltd. This is an Open Access article distributed under the terms of Creative Commons Attribution License (http://creativecommons.org/licenses/by/3.0). This permits unrestricted use, distribution, and reproduction in any medium, provided the original work is properly cited. 


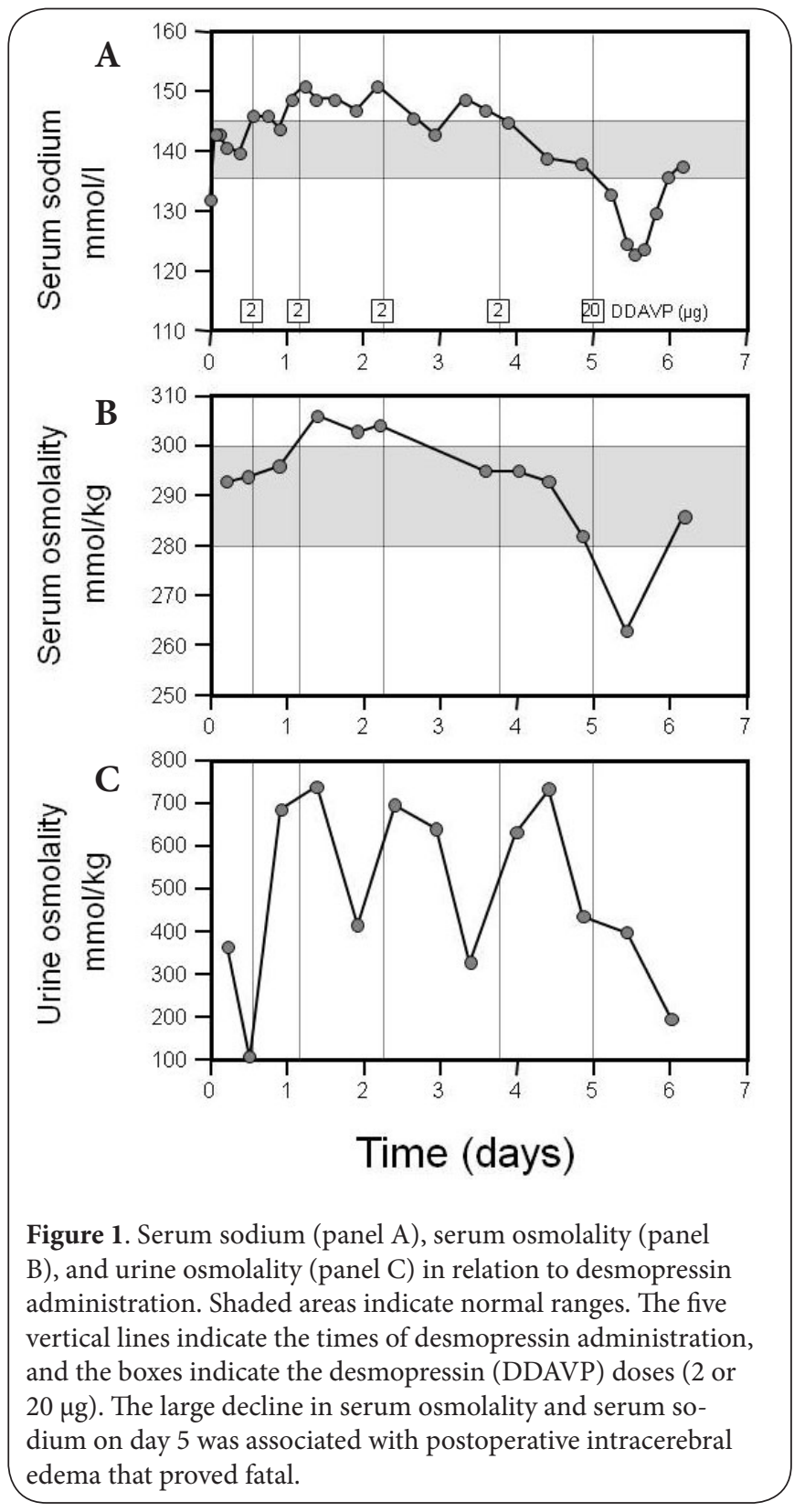

desmopressin. The patient also had been shown to have low-normal levels of von Willebrand factor (antigen, 0.75 [normal, 0.50-1.50 U/ml]; ristocetin cofactor activity, 0.65 [normal, 0.50-1.50 U/ml]).

Repeated neurologic assessment in the first five hospital days revealed response to verbal prompts, localization to pain, movement of all four limbs, pupils equal $(3 \mathrm{~mm})$ and reactive. On day five, he underwent surgical repair of Lefort I and II facial fractures. He remained intubated and ventilated, receiving midazolam $15 \mathrm{mg} / \mathrm{h}$ and morphine $25 \mathrm{mg} / \mathrm{h}$ for sedation and analgesia. Laboratory values on the morning of surgery included a hemoglobin of $81 \mathrm{~g} / \mathrm{L}$, platelet count $172 \times 10^{\%} / l$, international normalized ratio (INR) 1.1 , activated partial thromboplastin time (APTT) $27 \mathrm{sec}$, urea $2.0 \mathrm{mmol} / \mathrm{l}$, creatinine $37 \mu \mathrm{mol} / \mathrm{l}$, sodium $138 \mathrm{mmol} / \mathrm{l}$, potassium 3.4 $\mathrm{mmol} / \mathrm{l}$, chloride $106 \mathrm{mmol} / \mathrm{l}$, serum osmolality $282 \mathrm{mmol} /$ $\mathrm{kg}$. To secure hemostasis, the following treatment plan was implemented: desmopressin, $20 \mu \mathrm{g}$ (maximum dose for patient weighing $94 \mathrm{~kg}$ ) 30 minutes prior to surgery (ordered by the hematology service); tranexamic acid (anti-fibrinolytic agent), $1 \mathrm{~g}$ iv q8h; and platelets as required.

General anesthesia was induced with propofol and rocuronium, and maintained with oxygen/air mixture and $2.0-2.5 \%$ end-tidal sevoflorane. Surgery was performed without technical difficulties or need for platelet or cryoprecipitate transfusions; there was moderate blood loss $(\sim 1000 \mathrm{ml})$." During the $5.5 \mathrm{~h}$ surgery, the patient received $6250 \mathrm{ml}$ crystalloid (5000 $\mathrm{ml}$ Ringer's lactate; $1250 \mathrm{ml} 0.9 \%$ sodium chloride), $1000 \mathrm{ml}$ pentaspan, and 2 units of red cell concentrates. Intraoperative urine output was approximately $1000 \mathrm{ml}$.

Postoperatively, the intravenous fluid was changed to $2 / 3$ D5W-1/3 isotonic saline, given at $150 \mathrm{ml} / \mathrm{h}$. Blood work on arrival to the intensive care unit showed hemoglobin $66 \mathrm{~g} / \mathrm{l}$, platelet count $146 \times 10^{9} / \mathrm{l}$, INR 1.2 , APTT $31 \mathrm{~s}$, urea $2.1 \mathrm{mmol} / \mathrm{l}$; creatinine $33 \mu \mathrm{mol} / /$; sodium $133 \mathrm{mmol} / \mathrm{l}$, potassium $3.9 \mathrm{mmol} / \mathrm{l}$, chloride $102 \mathrm{mmol} / \mathrm{l}$, and glucose $6.3 \mathrm{mmol} / \mathrm{l}$. Four hours later the patient developed seizures. His pupils were fixed and dilated, he was non-responsive to stimuli, and no brainstem reflexes could be elicited. At this time, the patient's serum sodium had fallen to $123 \mathrm{mmol} / \mathrm{l}$, and the serum osmolality was only $263 \mathrm{mmol} / \mathrm{kg}$. A CT scan showed cerebral edema, with $5 \mathrm{~mm}$ midline shift and subfalcine transtentorial and cerebellar tonsillar herniation; previous areas of contusion seen on admission CT imaging were unchanged. The neurologic status did not improve after decompressive craniectomy and insertion of a ventricular drain; brain death was declared after repeat $\mathrm{CT}$ scan imaging showed severe diffuse cerebral edema and loss of gray-white differentiation. Post-mortem examination showed acute severe cerebral edema as well as parenchymal hemorrhage consistent with the history of head trauma 5 days earlier.

\section{Discussion}

Several lines of evidence suggest that desmopressin-associated hyponatremia-occurring in the setting of liberal intra-/postoperative administration of crystalloid-played a significant contributory role in the cerebral edema and transtentorial herniation. The serum osmolality fell from 293 to $263 \mathrm{mmol} / \mathrm{kg}$ over 24 hours, with the largest component of this fall (from 282 to $263 \mathrm{mmol} / \mathrm{kg}$ ) occurring in association with desmopressin administration. The corresponding abrupt desmopressin-associated decline in serum sodium was from 138 to $123 \mathrm{mmol} / \mathrm{l}$. Relatively low urine volumes were observed during and within 4 hours of surgery 
(2000 $\mathrm{ml}$ urine volume compared with $8400 \mathrm{ml}$ intravenous fluids administered); further, the postoperative urine osmolality $(400 \mathrm{mmol} / \mathrm{kg})$ was inappropriately concentrated in relation to the serum sodium concentration of $123 \mathrm{mmol} / \mathrm{l}$, implicating the antidiuretic effects of desmopressin.

In addition, cerebral edema is a known consequence of severe, acute hyponatremia $[10,11]$. Brain cells are able to adapt to hyponatremia if it occurs slowly, by exporting intracellular potassium and chloride and organic osmolytes including taurine, glutamine, glycerophosphorylcholine and myoinositol [12]. This allows maintenance of brain cell volume. A review [13] of published cases of hyponatremia suggested that humans tolerate hyponatremia if the rate of decrease of serum sodium concentration is $\leq 0.5 \mathrm{mmol} / \mathrm{l} / \mathrm{h}$. In this case, the decrease in serum sodium from 138 to 123 $\mathrm{mmol} / \mathrm{l}$ over approximately 16 hours, a rate of change of $0.92 \mathrm{mmol} / \mathrm{l} / \mathrm{h}$, was considerably higher than the rate that the brain can adapt to, and almost certainly was the most important factor leading to acute cerebral edema.

In this patient, the consequences of acute hyponatremia may have been exacerbated by the hypernatremic prodrome (related to neurogenic diabetes insipidus) (Figure 1A). Given that brain cells adapt to hypernatremia by increasing brain solute content, we conjecture that the preceding three-day period of hypernatremia may have made the brain less able to respond to the subsequent acute hyponatremia, since it was recently in the process of responding to an increase in serum sodium concentration.

Other potential contributing effects were the patient's brain injuries secondary to trauma sustained five days earlier and the concurrent surgery for this; thus, the role of delayed onset of cerebral edema from preceding head trauma alone cannot be ruled out. However, the close temporal relationship between onset of seizures, coma, and brain death, and desmopressin-associated hyponatremia, implicate at least an important contributory-if not predominant-role of desmopressin in explaining the patient's abrupt neurological demise.

Symptomatic hyponatremia is a common complication of prophylactic use of desmopressin for bleeding disorders, especially in young patients. A prospective study of 41 children with von Willebrand disease who received desmopressin for otolaryngologic surgery found mild hyponatremia (130-135 $\mathrm{mmol} / \mathrm{l})$ in $66 \%$ of patients, and severe hyponatremia $(<130$ $\mathrm{mmol} / \mathrm{l})$ in two (5\%) patients, one of whom developed seizures [14]. A retrospective study of 53 children who underwent serum sodium measurements after receiving prophylactic intravenous desmopressin for von Willebrand's disease and adenotonsillectomy found that $51 \%$ developed mild hyponatremia, and $3(6 \%)$ developing severe hyponatremia, one with seizures [15]. A series of 19 adults receiving intranasal desmopressin for von Willebrand disease or hemophilia found that $32 \%$ developed symptoms consistent with hyponatremia, with 1 patient developing severe hyponatremia (serum sodium, $124 \mathrm{mmol} / \mathrm{l}$ ) [16]. Recognized risk factors for desmopressin-associated hyponatremia include the young and the elderly, multiple doses, perioperative stress (elevated endogenous ADH levels), and administration of hypotonic fluids. Our patient was relatively young, had undergone major surgery, and was given hypotonic fluids postoperatively, illustrating the potential risk when transfer of care occurs and the implications of earlier administration of desmopressin are not recognized.

There are few examples in the literature of patients who have developed fatal complications associated with use of blood avoidance techniques. For example, a patient has been reported who developed fatal anaphylaxis associated with use of aprotinin given as a blood-conserving technique [17]. In our patient, fatal hyponatremia occurred in association with use of a common blood conserving medication, desmopressin, when relatively large volumes of intra-/postoperative crystalloid were given in the setting of recent hypernatremia. Given the known antidiuretic effects of desmopressin, with the potential for inducing hyponatremia and cerebral edema, the severe clinical course illustrates the importance of careful patient selection and appropriate perioperative management (e.g., avoiding excessive fluid administration) to ensure that the risk-benefit relationship of this blood conservation technique is optimal.

\section{Competing interests}

The authors declare that they have no competing financial or other interests.

\section{Authors' contributions}

JSM and TEW abstracted the clinical information; all four authors interpreted the data and wrote the manuscript.

\section{Acknowledgements and funding}

The corresponding author (T.E.W.) is funded by the Heart and Stroke Foundation of Ontario. The authors thank Jo-Ann I. Sheppard for preparing the figure.

\section{Publication history}

Editor: Paul Picton, University of Michigan, USA.

Received: 28-May-2012 Revised: 10-Aug-2012

Accepted: 24-Aug-2012 Published: 15-Sep-2012

\section{References}

1. Cobb, W. E., Spare, S. \& Reichlin, S.: Neurogenic diabetes insipidus: management with dDAVP (1-desamino-8-D arginine vasopressin). Ann Intern Med 1978, 88(2):183-188. | Article| PubMed

2. Goldsmith SR.: Vasopressin as a vasopressor. Am J Med 1987, 82(6):1213-1219. | Article

3. Mannucci, P. M.: Treatment of von Willebrand's Disease. N Engl J Med 2004, 351(7):683-694. | Article| PubMed

4. DiMichele, D. M. \& Hathaway, W. E.: Use of DDAVP in inherited and acquired platelet dysfunction. Am J Hematol 1990, 33(1):39-45. | Article | PubMed

5. Rao, A. K. et al.: Mechanisms of platelet dysfunction and response to DDAVP in patients with congenital platelet function defects. A doubleblind placebo-controlled trial. Thromb Haemost 1995, 74(4):1071-1078. | Article| PubMed

6. Crescenzi, G. et al.: Desmopressin reduces transfusion needs after surgery: a meta-analysis of randomized clinical trials. Anesthesiology 2008, 
109(6):1063-1076. | Article| PubMed

7. Weinstein, R. E. et al.: Severe hyponatremia after repeated intravenous administration of desmopressin. Am J Hematol 1989, 32(4):258-261. I Articlel PubMed

8. Bertholini, D. M. \& Butler, C. S.: Severe hyponatraemia secondary to desmopressin therapy in von Willebrand's disease. Anaesth Intensive Care 2000, 28(2):199-201. | Article| PubMed

9. Gomez Garcia, E. B., Ruitenberg, A., Madretsma, G. S. \& Hintzen, R. Q.: Hyponatraemic coma induced by desmopressin and ibuprofen in a woman with von Willebrand's disease. Haemophilia 2003, 9(2):232234. | Article| PubMed

10. Arieff, A. I., Llach, F. \& Massry, S. G.: Neurological manifestations and morbidity of hyponatremia: correlation with brain water and electrolytes. Medicine (Baltimore) 1976, 55(2):121-129. | Article| PubMed

11. Gross, P., Reimann, D., Henschkowski, J. \& Damian, M.: Treatment of severe hyponatremia: conventional and novel aspects. J Am Soc Nephrol 2001, 12 Suppl (17):S10-S14. | Article| PubMed

12. Pasantes-Morales, H., Lezama, R. A., Ramos-Mandujano, G. \& Tuz, K. L.: Mechanisms of cell volume regulation in hypo-osmolality. Am J Med 2006, 119(7 Suppl 1):S4-11. | Article| PubMed

13. Cluitmans, F. H. \& Meinders, A. E.: Management of severe hyponatremia: rapid or slow correction? Am J Med 1990, 88(2):161-166. | Article| PubMed

14. Jimenez-Yuste, V. et al.: Otolaryngologic surgery in children with von Willebrand disease. Arch Otolaryngol Head Neck Surg 2002, 128(12):1365-1368. | Article| PubMed

15. Allen, G. C. et al.: Adenotonsillectomy in children with von Willebrand disease. Arch Otolaryngol Head Neck Surg 1999, 125(5):547-551. | Articlel PubMed

16. Dunn, A. L. et al.: Adverse events during use of intranasal desmopressin acetate for haemophilia A and von Willebrand disease: a case report and review of 40 patients. Haemophilia 2000, 6(1):11-14. | Article| PubMed Abstract | PubMed Full Text

17. Oswald, A. M. et al.: Fatal intraoperative anaphylaxis related to aprotinin after local application of fibrin glue. Anesthesiology 2003, 99(3):762-763. | Article| PubMed

\section{Citation:}

Milkovic J S, Warkentin T E, Richardson R M A and Prebtani A P H: Fatal Hyponatremia Associated with Preoperative Desmopressin for Bleeding Disorder. journal of Anesthesiology and Clinical Science 2012, 1:11. http://dx.doi.org/10.7243/2049-9752-1-11 